\title{
ITF

\section{The impact of the four motivation boosters on tennis player development (part 1)}

\section{Antoni Girod (FRA)}

ITF Coaching and Sport Science Review 2015; 66 (23): 22 - 24

\begin{abstract}
The development of a tennis player is a long-term process. On average, the development of a high-level player takes ten years, during which time the coach's role is to help the player acquire the required technical, tactical, physical and mental skills. On the psychological level, one particular skill which reflects permanently on the development of all other skills is motivation. Its importance is such that even the slightest change in motivation, or temporary lack of motivation, can have a major impact on a player's entire game, performance on the court and, ultimately, long-term progress. Motivation is thus the fuel that a player needs to progress with consistency and determination on the road to the highest level. However, fuel alone is not enough: what you also need is an engine.
\end{abstract}

Key words: development, long term, psychology, progress Received: 26 April 2015 Accepted: 16 Juy 2015 Corresponding author: Antoni Girod Email: agirod@halifax.fr

\section{INTRODUCTION}

The role of the coach is to teach the player how to make good use of his fuel, i.e. motivation, by letting him discover the engine that will allow him to go higher and further. That special engine is made of 4 boosters, i.e. Meaning, Enjoyment, Progress and Performance, all of which need to be activated and combined according to the time and circumstances. The best way for a developing player to understand the subtle mechanics of these boosters is to follow in the footsteps of those who have successfully made the transition to the top level. To this end, each booster will not only be defined and explained in detail but also, and above all, illustrated by many examples of champions who will reveal the secrets of how their motivation has enabled them to get where they are.

\section{THE "MEANING" BOOSTER}

The Meaning booster is, without the shadow of a doubt, the most powerful of all four. In the initial stages of the young player's learning process, this booster takes the form of a dream. Dreams are a fantastic source of inspiration and motivation. "All the major achievements began as a dream in someone's head", as Einstein once said. There are different categories of tennis players: first, there are players who don't have any dream, have no particular ambition and are just content with what they have. In general, they stay where they are and are not disappointed with their fate. Then, there are players who dream, but do nothing else. Their bedroom is full of shiny posters of players they admire, but they let their idols train and compete in their place. It's a comfortable way of dreaming. There are also tennis players who have a dream and act upon it to make it a reality. They keep dreaming until they encounter the first difficulties. When the hardships of competitive tennis fall upon them, they stop dreaming. Once they overcome the frustration and discouragement that come with shattered dreams, they move on and put their energy into something else, some other dream maybe. After all, there are other things in life than tennis! And finally, there are incurable dreamers; those players have a dream of tennis in their head, a beautiful image they get up with each morning and that inspires them day after day, no matter what. A dream that is so strong and deep that it enables them to move any mountain. A dream that is stronger than defeats, injuries, criticisms or sarcasms. A dream that is a combination of ambition and humbleness. The ambition to see big, raise their head high, look up and be guided by the light. The humbleness to progress step by step, make mistakes, start again, accept being in the dark before being in the spotlight. Sooner or later, these dreamers will find their way to show courts and magazine covers and lift the most coveted trophies. Their dream finally becomes a reality. And their reality becomes the dream of millions of players (Girod, 2009).

Here's an inspiring story told by Jelena Gencic, who was current world number 1 Novak Djokovic's first coach and also discovered Monica Seles in the late 1970s: "I'll never forget the day that little

boy came to my summer tennis camp in Kopaonik, carrying a gym bag with his belongings well in order, just like the professionals. I asked him who had prepared his bag for him and he replied that he had done it himself. I then asked him what does he want to become when he grows up. Without hesitation, he said: 'The No. 1 player in the world', which is also the answer Monica Seles had given me many years before when she was a little girl. That boy was Novak Djokovic." (New York Times,

2013).

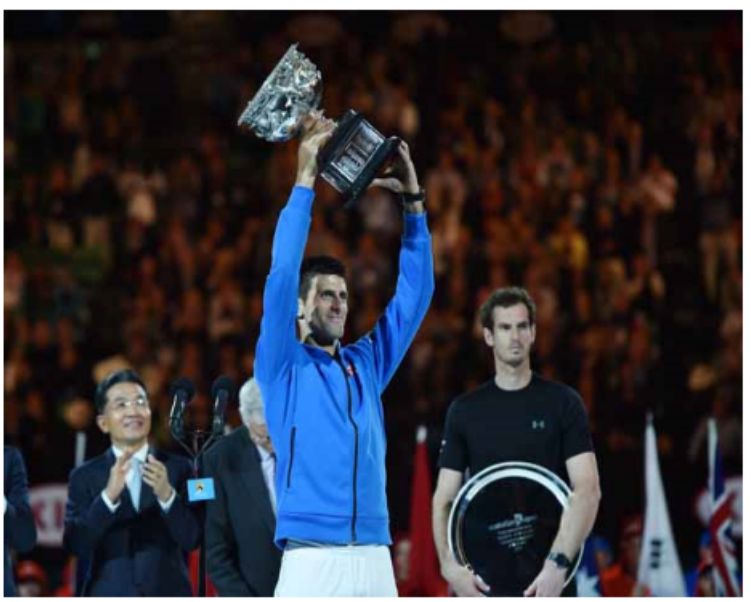

When a player becomes an adult, the Meaning booster must act as a complement to the initial dream. In times of doubt, when results are slow to come or routine sets in, it can enable 
the player to start afresh by allowing him to answer the following questions: What is the purpose of all this? Why? What is the point of hitting a tennis ball for hours? Why spend entire years doing something seemingly absurd like rallying with an opponent standing twenty meters in front of you? It is generally accepted that a tennis match is all about winning. However, there's never been, in the history of tennis, a player who has managed to win all his career matches. Losing is therefore also part of the game. Losing and winning are two sides of the same coin, i.e. competition. Therefore, the true meaning of the game is beyond the unique quest for victory. Otherwise, each defeat (and defeats are bound to happen) would inevitably leave the player feeling deeply frustrated and distraught by the absurdity of it all.

So, what is the basic meaning of the game? First of all, it must be said that tennis can be seen as a metaphor for all the possible situations that a human being may face during his life: a goal (putting the ball in play), an obstacle (the net), opposing forces (gravity, wind), dependence on others (the opponent, the chair umpire), other people's opinion (spectators), external boundaries (court limits) and internal boundaries (player himself). If the only reason to play is to win, then all these factors are likely to turn the player's life into a nightmare and tennis will eventually bring more suffering than enjoyment. On the mental level, a positive approach is to see the net as an opportunity to develop one's ability to overcome obstacles. Similarly, the wind can be seen as an opportunity to learn how to adapt. The opponent is no longer a dangerous enemy, but a demanding coach that forces you to bring out your best game. The calls, at times questionable, made by the umpire can be seen as an invitation to understand that there can be a point of view different than your own. The presence of spectators teaches you to face other people's opinion on you. The court limits force you to structure your actions and channel your energy. Being aware of your own limits is both an opportunity to determine the areas for improvement and overcome those limits. Whether you're a competitor in the making or a professional player, the ultimate purpose of the game (beyond the rankings, and the fame and money tennis can be bring), should be to learn to know yourself and others.

Djokovic's words illustrate this perfectly: "With all the great players currently involved in the race to the top, it's normal not to win all the time. So you have to stay consistent, keep your self-control and remain confident in your abilities, even when you lose. In sport, you win matches you should lose and lose others you should win. The key is to always have clear goals and to learn from your experiences. If I had not been the number 1 tennis player in the world, I would have liked to work in the field of psychology or philosophy because I am passionate about this aspect of human nature."

\section{THE "ENJOYMENT" BOOSTER}

For a young player in the early stages of his development, the enjoyment of the game is the most immediate booster there can be. Coming from a family of skiers, Djokovic would have followed in the footsteps of his father, but destiny, or more precisely the building of a tennis court just opposite his parents' restaurant in Kopaonik, decided otherwise. While helping the workers build the court, the little boy fell in love with the game and eventually asked his parents to buy him a racket. In the end, he chose to walk in the footsteps of his idol Pete Sampras. It is possible that the Serbian champion's exceptional mental strength comes from the time where the first court he ever walked on was built in the Serbian mountains, near the Kosovo border, a time where he was guided by his childhood dream and his love of the game. That being said, it is important early on to teach children that enjoyment is not always immediate. We must teach them to be patient and make them understand that the initial stages of tennis learning may be void of enjoyment. To overcome the frustration that stems from a lack of immediate enjoyment, it is essential to develop the ability to visualise future enjoyment.

In a famous experiment conducted by American psychologist Walter Mischel that took place at a Stanford nursery school using children aged four as subjects, the children could eat a marshmallow placed in front of them immediately or be rewarded with a second marshmallow if they chose to be patient. The majority of children, unable to wait, ate the marshmallow immediately. The few children who managed to be patient to get two marshmallows covered their eyes with their hands or started playing with their feet and hands not to give in to the temptation. They managed to control their urge and be patient to get the reward. In follow-up studies, Mischel continued to track the evolution of these children and found, more than twelve years later, quite spectacular differences between the subjects who had eaten the marshmallow immediately and those who had managed to delay gratification longer by controlling their emotions. Indeed, the small number of those who had controlled their emotions were more efficient, showed more confidence and demonstrated a greater ability to deal with the difficulties of life. They were less likely to experience doubt, fear of failure, and were able to keep their cool and remain clear-headed when under pressure. They showed confidence and greater resilience by striving to overcome challenges instead of simply giving up. When he was younger and the best player in his age category in Austria, Dominic

Thiem, one of the rising stars of the men's game, had a twohanded backhand and a very defensive style of play. Under the guidance of his coach Gunter Bresnik, he made the transition to a one-handed backhand and adopted a more aggressive style of play. "It was hard because as a result of all the changes to my game, my ranking plummeted. But I had total confidence in my coach and I knew that it would eventually pay off." This ability to not give in to the immediate temptation to preserve one's status in the short term, but instead be patient and work behind the scenes for the delayed gratification of obtaining more significant results in the longer run is very similar to what we learned from Walter Mischel's marshmallow experiment! The importance of the Enjoyment booster needs to be instilled from a young age. For example, the impact of the education that Rafael Nadal received from his uncle Toni, based on the importance of enjoyment, is evident in this interview given in 1999 by a young Rafael Nadal, then aged 12, after a semi-final loss to Richard Gasquet at the Les Petits As tournament held in Tarbes: "One very important thing is to have fun. If you play without having fun, it's really not interesting and then, there's no point in playing."

Another very striking example in relation to this notion of enjoyment is that of Kimiko Date. It should first be noted that the Japanese player took a break from professional tennis for a total of 12 years between 1996 and 2008. Here is how she explains the reasons for her comeback to the game: "When I retired from tennis at the age of 25 , after having been ranked number 4 in the world, I never would have thought that I'd miss the game. And then, for years, I worked as a tennis commentator for television. This outsider's perspective made me realise how beautiful and special this sport is. Over time, my state of mind changed. When I was young, my goal was to be a top 10 player and therefore I was constantly under pressure. Playing tennis was not a lot of fun back then. But when I came back to the game in 2008 is when I really discovered the enjoyment of the game, even when I was losing. I have a lot of passion for the sport. And I love the challenge that I have set 
for myself, because it is not easy at my age." What she experienced in the first part of her career is typical of what many male and female players go through when "performance" is their only motivation booster. Obsessed with rankings, wins and glory, they eventually lose sight of the essence of the game, i.e. enjoyment. It's only when she took a step back that she realised the beauty of the sport and that her desire to play came back. Knowing when and how to take a break to step away and get a new perspective allows you to not give too much importance to performance and to refocus on the enjoyment of the game.

\section{CONCLUSION}

Motivation is a key part of the development of a young tennis player. It's important to follow in the footsteps of those players that have succeeded in transitioning to the top level and a way of ensuring this is to activate the 4 boosters; meaning, enjoyment, progress and performance.

\section{REFERENCES}

Girod, A. (2009). Tennis. La préparation mentale. DB Book. Mischel, W. (2015). Le Test du marshmallow. JC Lattès.

New York Times (2013).

http://www.nytimes.com/2013/06/03/

sports/tennis/03iht-coach03.html?_r=0
RECOMMENDED ITF TENNIS ACADEMY CONTENT (CLICK BELOW)

\section{ITF Academy}

Copyright (c) Antoni Girod 2015

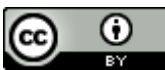

This text is under a Creative Commons BY 4.0

license

You are free to Share - copy and redistribute the material in any medium or format - and Adapt the content - remix, transform, and build upon the material for any purpose, even commercially under the following terms:

Attribution: You must give appropriate credit, provide a link to the license, and indicate if changes were made. You may do so in any reasonable manner, but not in any way that suggests the licensor endorses you or your use.

CC BY 4.0 license terms summary $\quad$ CC BY 4.0 license terms 